\title{
Assessing Formal Independence of Data Protection Authorities in a Comparative Perspective
}

\author{
Philip Schütz \\ Fraunhofer Institute for Systems and Innovation Research, Karlsruhe, Germany \\ philip.schuetz@isi.fraunhofer.de
}

\begin{abstract}
Data protection authorities (DPAs) represent one of the key actors, not only when it comes to the execution of privacy and data protection policies, but also in terms of awareness raising, consultancy and networking. Since they comprise the spearhead of regulators in the field of privacy and data protection regulation, their independence from the private as well as political domain becomes of the utmost importance. However, independence turns out to be a multifaceted concept. That is why this contribution discusses ways of assessing DPAs' independence, drawing on research about independent regulatory agencies (IRAs). Three country case studies are finally presented.
\end{abstract}

\section{Introduction}

Embedded in a dissertation project that is dedicated to a comparative analysis of data protection authorities (DPAs) 1 this paper aims to shed light on a central feature of DPAs, namely their independence. Since there is little systematic and long-term research on DPAs from a political science perspective, the theoretical foundations of and methodological approaches to independent regulatory agencies (IRAs) can help to serve as a template model providing a framework for the analysis of DPAs.

IRAs represent a crucial instrument of the regulatory state, which is characterized by ongoing deregulation, increased delegation and reregulation processes [1|23]. They comprise a relatively new attempt to cope with societal challenges that elude traditional models of governance. The EU Data Protection Directive makes use of this instrument, stipulating mandatory supervisory authorities, which have to fulfil a variety of different functions. DPAs are not only expected to serve as ombudsmen, auditors, consultants, educators, policy advisers and negotiators, but they should also be able to enforce changes in behaviour, when private or public actors violate data protection legislation [4, p. 135].

Most importantly, as opposed to most IRAs, DPAs are not only tasked with the supervision of private entities, such as companies in various business sectors, but they are also expected to watch over public authorities, i.e. executive, legislative and judicial

\footnotetext{
${ }^{1}$ Data protection authority refers in the following text to the term of supervisory authority, stipulated in the Directive 95/46/EC, art. 28 [21]. This contribution solely deals with DPAs on the national level, although the regional and international, particularly the EU level, would be interesting to look at as well.
} 
institutions and bodies 2 Despite the traditional checks and balances in a democratic and constitutional state, the monitoring of governmental bodies by an authority closely linked to the government is particularly new in the theoretical framework of the regulatory state and IRAs. Since "[w]e are not normally accustomed to think of government as 'regulating' itself" [5, pp. 3], the setting up of DPAs by political actors in order to exercise control over the same presents an interesting and new aspect in the theory of regulation. Thus, the concept of independence in this context seems to require special attention.

As a final remark, the author wants to emphasize that this work displays the starting point of the above mentioned dissertation project. The text should therefore be considered as exploratory and tentative, reflecting new ideas to examine the role of DPAs in society.

\section{The Concept of the Regulatory State and Independent Regulatory Agencies}

Whereas strategies of stabilization and consolidation, which included centralised administration, state ownership and planning, mainly shaped the political programs of the 50s and 60s in most West European countries, privatisation and deregulation dominated the policies in the 70s and 80s, strongly influenced by the American model [1, p. 77].

Today's regulatory state represents, in many ways, a mélange between the dirigiste and the neoliberal state of the preceding decades. On the one hand the state continued, throughout the 90 s, to retreat from sectors which were once publicly owned. On the other hand, the state "reregulates the now-liberalized markets [and sectors] with less intrusive instruments" [6, p. 873]. Rather than direct state intervention, reregulation ideally implies the idea of improving "the efficiency of the economy by correcting specific forms of market failure such as monopoly, imperfect information, and negative externalities" [1, p. 79]. Yet, imposing rules on highly dynamic and innovative sectors has turned out to be highly problematic and extremely difficult.

Eventually, the evolution of the regulatory state in Europe was closely linked to the growing importance of the European Union. Since the EU neither represents a federal state nor a confederation but rather made it necessary to redefine the term "union" as a new form of federation sui generis, based on the idea of a multilevel governance [7], EU legislation was designed to be regulatory rather than redistributive [8, p. 39].

However, whether or not the EU can thus be considered a regulatory state remains a controversial debate; also because it is highly contested as to which political level is actually responsible for most of the regulations, as well as the most important ones [9].

A distinguishing attribute of the regulatory state is reflected in the concept of delegation, which, contrary to privatisation, describes the transfer of authority and responsibility from the state to another private or public organisation without being completely exempt from accountability. Delegation of sector specific regulation assignments to

\footnotetext{
${ }^{2}$ Of course, there are additionally numerous data protection commissioners and officers in private companies and governmental organisations working together with DPAs on the international, national and regional level. However, they will not be part of the analysis in this paper.
} 
IRAs is an essential and prevalent tool of the regulatory state. Yet, the historical origins of IRAs in Europe date back to the early postwar years, when Britain and Germany introduced independent competition authorities [10]. Even prior to that, IRAs in the United States had become an integral part of the governmental agency landscape, typically operating outside the federal executive departments. Today, the model of independent central banks, which has been rapidly spreading throughout Europe and the rest of the world, is considered as one of the main archetypes of IRAs [11, p. 267].

IRAs can be defined as "a body with its own powers and responsibilities given under public law, which is organizationally separated from ministries and is neither directly elected nor managed by elected officials." [12, p. 956] As the name already suggests, independence from governmental influence plays an essential role in the conception of IRAs.

Yet, it seems surprising that the state is willing to accept a loss or at least a reduction of control and power in certain regulatory sectors. Gilardi identifies several reasons for this transfer of competencies to IRAs [13, pp. 102]. One of the most important causes involves the objective of governments to reduce their decision-making costs by e.g. taking advantage of IRAs' specialised expertise in the relevant field of regulation. "Faith in the power of expertise as an engine of social improvement - technical expertise which neither legislators, courts nor bureaucratic generalists presumably possess - has always been an important source of legitimisation for regulators." [3, p. 152] Moreover, due to their independence IRAs are not only more flexible in adjusting regulations to changing conditions, but they also work more effectively and efficiently, presenting better regulatory outputs than traditional bureaucracies. They tend additionally to organise their decision-making processes in a more open and transparent way and eventually policy makers are able to profit from shifting blame to IRAs when regulation fails to succeed.

However, the most convincing argument as to why governments delegate power to IRAs is offered by the credibility hypothesis. Since "politicians have few incentives to develop policies whose success, if at all, will come after the next election [...], it is difficult for political executives to credibly commit themselves to a long-term strategy." [3, p. 153] Being exempt from elections and the associated political short-term thinking, IRAs are able to fill this credibility vacuum. They can provide a certain time consistency in their policies leading to a more "stable and predictable regulatory environment" [13. p. 102]. Fearing rapid changes in popular support, governments have, after all, an interest in preserving their policy achievements through IRAs, in order to prevent future parties in power from altering them too easily.

\subsection{Independence of IRAs}

Even though the concept of IRAs' independence seems to be rather straight forward, it is in fact highly complex, implying different nuances and dimensions. In order to exemplify the challenges in trying to assess the independence of IRAs, two empirical studies are briefly discussed.

Though being confronted with operationalisation and quantification problems, Gilardi has developed an independence index concentrating on formal, i.e. legally stipulated, independence [6]. The comparative analysis embraces 33 IRAs from five different regulatory sectors in seven European countries. Originally developed by 
Cukierman et al. in a comprehensive study focused on measuring the independence of central banks [14], the index involves five groups of indicators: The agency's head status, the management board members' status, the general frame of the relationships with the government and the parliament, financial and organizational autonomy, and the extent of delegated regulatory competencies [6, pp. 880]. Whereas the first two groups comprise indicators such as the term of office as well as procedures of appointment and dismissal of the agency's head/board members, the other three contain, inter alia, accountability arrangements towards the government and parliament, sources of the agency's budget and the degree of exclusive regulatory power by the agency. In order to avoid subjective valuation, he attributes the same weight to each of his 21 indicators 3

Although Gilardi succeeds in providing a systematic overview of variables that supposedly affect the autonomy of IRAs, the index has several shortcomings such as equating breadth of powers with degree of independence as well as the absence of provisions prohibiting an action with the permissibility of that action [15, pp.5]. Most importantly, the analysis ignores sources of influence beyond legal provisions. These informal aspects, however, are decisive in determining the de facto independence of IRAs [16]. Thus, it is crucial to bear in mind that "some regulators can be independent in practice without being independent on paper." [17, p. 2]

Thatcher, in contrast, includes variables that reflect informal sources of influence into his comparative study of 23 IRAs from eight different sectors in four countries 4 He not only examines politicization of regulators, but also expands his analysis to possible dependencies on regulatees from the private sector, operationalised by the percentage of IRA members formerly or subsequently active in regulated business and industry (revolving doors). Moreover, the influence of IRAs on decision-making processes is scrutinised. Thatcher concludes: "Having created IRAs, governments do not use their most visible formal powers to control them, with the exception of limiting IRA's resources (and the partial exception of politicization in Italy)." [12, p. 966] Nonetheless, sharp conflicts are frequently carried out between IRAs and the private sector, including legal action. IRAs, eventually, appear to be separated from business by and large, meaning that the revolving door phenomenon occurs rather seldom except in Great Britain.

Despite taking a broader range of variables into account, Thatcher's analysis raises the question of whether quantitative methods alone are capable of assessing a multifaceted concept such as independence in its full complexity. Quantifying independence, particularly in the form of an index, is vulnerable to oversimplification, most notably in the process of operationalisation. Besides, there is the risk of failing to consider less

\footnotetext{
${ }^{3}$ As an example, the indicator "term of office" (of the agency's head) can have six different parameters: "Over 8 years", "6 to 8 years", "5 years", "4 years", "fixed term under 4 years or at the discretion of the appointer", and eventually "no fixed term". Each parameter is assigned a value evenly spread between 1 (= complete independence) and 0 (= no independence). Since there are six parameters, the assigned values are accordingly: 1, 0.8, 0.6, 0.4, 0.2, 0. Here, the basic assumption is that the longer the term of office lasts, the more independent the agency's head becomes.

${ }^{4}$ His analysis is based on five groups of indicators: Party politicization of regulators, departures of IRA members before the end of their term, official tenure of IRA members, financial and staffing resources as well as the use of powers by elected politicians to overturn IRA decisions [12 p. 959].
} 
tangible variables that are decisive in determining de facto independence. In order to enhance the significance of research on IRAs' independence, the integration of qualitative research tools would be expedient.

However, both of the studies not only identify, discuss and systematise factors influencing formal independence, they also pave the way for further research drawing attention to the importance and complexity of IRAs' independence. Seemingly simple questions such as "Who is independent (the agency or single officials)?" and "Independence from whom (public or private actors)?" turn out to be difficult to answer.

In this context, the relationship between de jure and de facto independence deserves further attention. As opposed to what one might assume, the logical link between the two is apparently subject to scientific debate. Whereas Maggetti and Gilardi, in later studies, find out that "formal independence is neither a necessary nor a sufficient condition for regulators' de facto independence from political decision-makers and from the regulated industries" [16][17, p. 1], Hanretty, Hayo and Voigt's research suggests a high degree of correlation [18]19].

Although the role of IRAs, and later DPAs, can not be sufficiently understood by restricting the analysis only to their formal independence, legal provisions represent a good starting point, enabling political scientists to compare expectations and reality.

\section{The EU Data Protection Directive and the Role of DPAs}

Directive 95/46/EC represents the most comprehensive and influential legislative framework regarding the protection of personal data. From the start of the Directive's development it became clear that "data protection had ceased to be merely a human rights issue; it was also intrinsically linked to the operation of international trade [4, p. 93].

Aiming to create a more homogenous legal and economic sphere to guarantee the free flow of data across European borders, the Directive, which took over five years of tough negotiations from first draft to adoption, was therefore mainly developed in the Internal Market portfolio of the EU Commission [20 p. 91]. Furthermore, the economic argument not only helped to persuade stakeholders of the Directive's benefits, but also provided a legal basis, namely Article 100a of the EC Treaty, which seeks, inter alia, "to ensure the establishment and functioning of the Internal Market".

Since then, the Directive has not only facilitated the transborder flow of personal data within the EU, but has also contributed to higher minimum standards of data protection in quite a few Member States. Due to the fact that EU directives are supposed to be binding, each Member State has, at least formally, implemented comprehensive data protection provisions. Although these provisions have not been able to keep pace with the technological developments and new emerging threats to privacy, the Directive, which is currently under revision, still constitutes one of the most advanced legal frameworks in the field of data protection worldwide.

The European Data Protection Directive also stipulates the mandatory set up of data protection authorities, the so-called supervisory authorities [21, art. 28]. This has mainly been done to harmonise the responsibilities of DPAs, which were quite different in data protection provisions of the Member States developed prior to the EU Directive. Sweden, for example, relied on a licensing model, whereas the French government 
chose a more selective approach and Germany provided for subsequent monitoring as well as recommendations rather than binding decisions [22, pp. 134].

As mentioned earlier, one of the most distinctive features of DPAs is eventually their assignment to watch over private as well as public actors. This is contrary to the work of most IRAs, monitoring (financial) markets or the utilities sector. Here, DPAs comprise an interesting aspect, namely the idea of an authority that was created by the state in order to control the same. Hood et al. deal with this new facet of regulation, identifying huge deficits in the actual transposition of the concept [5, p. 223]. Hence, the issue of independence especially from governmental influence requires extra attention.5

\subsection{Independence of DPAs}

Although the majority of IRAs face similar conflicts concerning their continuous struggle for independence, DPAs are particularly under threat of being held in check by public authorities. Since the state not only delegates power to DPAs, but could additionally be subject to harsh criticism and potentially strict regulations itself, public actors have an increased interest in manipulating the output and outcome of DPAs' actions. Maybe that is why the Directive has specifically stated that DPAs "shall act with complete independence in exercising the functions entrusted to them" [21, art. 28, para. 1] 6

Nonetheless, the legal and political reality in EU countries shows that extremely diverse interpretations of the term "complete independence" are prevalent. Even though the goals stipulated in the Directive are supposed to be binding, Member States are granted some latitude in working out the details of the finally implemented national legislation [23]. That is why the legal set up and status of DPAs varies from country to country or in a federal state like Germany even from Land to Land. These legal details, however, can determine what kind of powers and tasks are delegated as well as whether or not DPAs are able to work independently and hence effectively 7

\section{Case Selection}

In the following section Germany, Poland and Sweden have been chosen to serve as an example to demonstrate how much room for interpretation of the term "complete independence" sometimes remains.

Aiming at a comparative analysis of DPAs in EU Member States, the thesis comprises a so-called most similar systems design. Yet, European countries differ, sometimes immensely, in their national policy styles, deriving from their distinct historical

\footnotetext{
${ }^{5}$ Dealing with formal independence features, this work will mainly neglect the relationships between private businesses and DPAs, which are usually of a rather informal nature.

${ }^{6}$ Even though „,complete independence“ is the term used in the EU Directive, there is no institution, organisation or individual who can claim to be complete independent. However, the wording refers to the increased relevance the European Union put into the autonomous status of DPAs.

${ }^{7}$ Despite initial leaning towards transposing and applying Gilardi's independence index to the analysis of DPAs, the author has refrained from attributing a numerical value to the formal independence status of DPAs due to the early stage of research and insufficient robustness of such an index.
} 
experiences and culture. Assuming that these policy styles have an influence on the set up of DPAs, it seems expedient to choose a rather heterogeneous sample. Here, Castles ‘ classification of Western democracies into families of nations offers an approach to start from [24].

He identifies an Anglo-Saxon, Scandinavian, Continental and South European country group, which are each characterised by distinctive policy traditions [25] 8 Thus, the sample should include four EU Member States, one out of each country group. Since the EU enlargement after the Cold War has changed the composition significantly, East European countries should be considered as a separate country group as well.

That is why DPAs of Great Britain, Sweden, Germany, Spain and Poland have been selected as case studies within the dissertation project. Due to the early stage of the empirical analysis, this paper will only discuss three cases, of which Germany represents the most elaborated and assessed one.

\subsection{The German Case}

In Germany, where DPAs have a long tradition at the national (since 1978) as well as regional levels (in Hesse since 1970), independence has always been an essential element of data protection institutions [26]. Supporting this point, German DPAs even served as a role model in the process of developing the EU Data Protection Directive.

Lately, however, the governmental interpretation of independence in Germany has come under closer scrutiny. Because Germany is a federal state, regulatory powers were given to the national DPA, i.e. the Federal Commissioner for Data Protection and Freedom of Information (FfDF) as well as to his regional equivalents on the Länder level 9 Over the years, a differentiation process has been taking place between the two levels. Today, the FfDF is responsible for data protection issues concerning federal public institutions and their policies, whereas DPAs of the Länder monitor the public sector on the regional level as well as, most remarkably, non-public bodies, inter alia private enterprises, within their territory.

Consequently, some Länder governments launched specific governmental agencies, which were put in charge of supervising non-public corporations in regards to their compliance with data protection law. The close ties between the government and the regulating agencies especially, caused the EU Commission as well as the European Data Protection Supervisor (EDPS) to file a suit against the Federal Republic of Germany for infringement of the "complete independence" principle.

In March 2010 the European Court of Justice (ECJ) ruled that Germany "failed to fulfil its obligations under the second subparagraph of Article 28(1) of Directive 95/46/EC“, i.e. the assurance of „,complete independence“ [27]. And indeed, the ECJ

\footnotetext{
${ }^{8}$ The categorisation is mainly based on differences in the division of labour between the state and the market resulting in different regulation cultures, traditions and strategies. Although Castles' families of nations have not yet been applied to the policy field of data protection and DPAs, the concept seems to be promising with regard to delivering a rather heterogeneous set of country samples.

${ }^{9}$ Although specific DPAs of the Länder will be scrutinised more thoroughly within the dissertation project, this paper will not deal with the regional level in more detail.
} 
confirmed that some governments of the German Länder had appointed specific "authorities [to be] responsible for monitoring the processing of personal data by nonpublic bodies and undertakings governed by public law which compete on the market (öffentlich-rechtliche Wettbewerbsunternehmen)“ [27, para. 56].

Furthermore, the court devoted much attention to the clarification of the meaning of "complete independence". The ECJ stated "that a supervising authority must be free from any influence, whether that influence is exercised by other authorities or outside the administration. The fact that these DPAs are subject to State scrutiny in Germany constitutes an infringement of that requirement." [27, para. 15] Apparently, some Länder governments had a narrower interpretation of "complete independence" in mind, proposing the concept of "functional independence" in the sense that DPAs must be primarily independent of regulatees from the private sector [27, para. 16].

And despite the judicial decision of the ECJ, also the independence of Germany's FfDF seems jeopardised, since there is a significant number of gateways and possibilities of governmental influence.

The Federal Commissioner in Germany represents not only the head of the national DPA but also the DPA as an institution itself. Though being civil servants, DPA officials are actually working directly for him/her. While the FfDF's basic number of staff amounts to 90 [28, p. 1055], the annual budget, which is a part of the Federal Government Budget and therefore determined by both chambers of the legislature, totals around 8.8 million Euros [29, pp.36].

Although being elected by the German Bundestag following an amendment to the Federal Data Protection Act in 1990, the Commissioner is, in fact, appointed at the suggestion of the Federal Government [28, p. 1053] [30, sec. 22, para. 1]. Moreover, he/she can only be dismissed due to a charge of serious misdemeanour equivalent to that which would justify the dismissal of a judge with tenure [30, sec. 23, para. 1].

Most remarkably however, the FfDF is organizationally attached to the Federal Ministry of the Interior, which has several problematic consequences to it. Even though the commissioner remains, in general, independent from any instructions or orders (functional supervision) by the government, which is specifically stipulated in the national data protection act [30, sec. 22, para. 4], he/she is exposed to the administrative supervision by the ministry.

According to Dammann, a legal scholar and former top official working for the FfDF, the administrative supervision could not only offer ways to seriously hamper DPA's work, but also result in a so-called "anticipatory obedience" by the commissioner [28, p.1057]. Dammann, furthermore, points to the fact that the national DPA is actually a way station for civil servants of the Ministry of the Interior, where they will normally continue their career later on [28, p.1058]. This is highly problematic in terms of the staffs' de facto commitment, orientation and willingness-to-comply.

Additionally, the FfDF is not in a position to decide on his/her personnel policy independently [30, sec. 22, para. 5, cl. 5], since the ministry has a say in it, as well. In cases of a promotion or "voluntary" transfer of an employee, the authority even lies exclusively with the ministry [28, pp.1057]. Finally, the commissioner is subject to legal supervision by the government [30, sec. 22, para. 4, cl. 3], which constitutes another potential source of governmental influence. All of this is particularly critical, since the 
Ministry of the Interior is traditionally in charge of often privacy-invasive national security policies, comprising a classical field with the need of privacy regulations by the FfDF.

\subsection{The Polish DPA}

Poland does not have a long history in data protection legislation. The Act on the Protection of Personal Data is relatively new and came into force in 1997, seven years prior to the accession to the European Union, with important amendments in 2002 and 2004 [31]. Since Poland is, unlike Germany, a unitary state, the Inspector General for Personal Data Protection represents the key regulatory authority. An office, the so-called Bureau, which has a budget of 13.7 million zloty, approximately $3.3 \mathrm{~m}$ Euros, assists his work [32]. The Inspector General (IG) is, moreover, elected and can only be dismissed by the Polish Diet with the concent of the Senate [31, art. 8, para. 2/8].

Although independence is not specifically stated in the data protection legislation, the Polish DPA has far-reaching discretion in influential domains such as personnel policy and budget control. Contrary to the non-existent formal independence in personnel policy decisions of the German FfDF, the Polish IG is ,,vested with the powers and obligations as an employer in relation to the people employed in the Bureau. " [33, art. 2, para. 2, cl. 210 That way, on the one hand, any kind of financial control over the staff of the IG by the government is being avoided. On the other hand, not being civil servants, employees of the Polish DPA might suffer from lower quality social security and pension schemes.

Within the annual Budget Act the parliament provides the Bureau with financial resources which are then managed and controlled by an independent Chief Accountant within the DPA [34, art. 9]. The presentation of an annual report to the parliament about the DPA's activities, "including conclusions with respect to observance of the provisions on personal data protection" [31, art. 20], underpins the special ties of the IG to the parliament.

All in all, the Polish DPA appears to be formally independent from governmental influence mainly due to the absence of a ministry that supervises his/her actions. Contrary to initial assumptions, the relative newness of and little experience with data protection legislation in Poland has not had a negative effect on the formal independence of the DPA. Also relevant is, of course, the country's communist past, which will be taken into further consideration within the thesis.

\subsection{The Swedish Data Inspection Board}

Sweden was the first country that not only institutionally dealt with the political topic of data protection in setting up a Royal Commission on Publicity and Secrecy in 1969, but also developed the first national data protection legislation worldwide in 1973 [35. p. 59/63].

${ }^{10}$ The statute that stipulates the principles of organisation and functioning of the Bureau is, however, granted by a regulation (ordinance) of the President of the Republic of Poland [31, art. 13, para. 3]. 
Since then, the Swedish Data Inspection Board (DIB) has represented the central national regulatory body in the field of data protection. In 2007, however, the Commission on Security and Integrity Protection was established as an additional sectoral supervisory authority, being assigned to monitor the compliance with data protection legislation of law enforcement agencies [36]. Despite the activities of the Commission, even the government itself is able to issue regulations e.g. for exemptions to prohibitions regarding the transfer of personal data to third countries or notification of certain types of data [37, sec. 35/36]. This is why the DIB seems to lack exclusive regulatory power in the field of data protection.

Headed by the Director General (DG), the DIB employs 40 people [38, p. 5] and allocates 37 million SEK [39], round about 4m Euros, annually. Whereas DPAs in Germany and Poland clearly orientate themselves towards the commissioner model, Sweden follows the commission model, in which the head of the DPA does not represent the institution itself [40].

Nonetheless, the DG plays a significant role in the agenda-setting and policy-making processes of the authority. That is why it is astonishing that he/she is not only appointed but also directly employed by the government [41], which, of course, implies varied and significant leverage in cases of the government's disagreement with decisions of the DIB. However, dismissal procedures can only be initiated due to serious neglect of duties towards the employer [42]. In practice, a specific board consisting of five members, of which the chair and vice chair shall be lawyers and have experience as court judges, decide upon the actual dismissal of the DG [43].

According to Flaherty, one of the most significant sources of governmental influence in the past involved the Minister of Justice's capability to "wield [influence] in negotiations over the DIB's budget with the Minister of Finance" [44, p. 114] 11 This still seems to be the case since the DIB is financed through allocations from the State budget, which are based on a so-called regeringsbeslut determined by the Ministry of Justice [39].

The strong ties between the Ministry and the DIB also make autonomous personnel policy decisions more difficult, although, officially, the Swedish DPA is supposed to employ its own staff [46, para. 9] [47] [41, para. 25].Furthermore, there are a variety of accountability relationships towards the Ministry, such as the obligation to ensure efficiency, which could be used to exercise control over the DIB [41, para. 3/28/29].

However, most importantly, neither the discussed procedural provisions concerning the appointment, term of office and dismissal of the DG, nor the financial and personnel policy issues are part of the Personal Data Act. Most of it can be found in specific ordinances which, contrary to acts, may be changed at will by the government.

Summing up, it does not appear to be appropriate to use the attribute "formally independent" in relation to the Swedish DPA. The provisions of the researched legal documents do not even get close to the "complete independence" requirement of the EU Data Protection Directive and its interpretation of the ECJ. However, what this finding

${ }^{11}$ That way, even a new self-financing model of the DIB was introduced in an amendment of 1982, which was aimed at cost recovery through licensing fees [44 p. 114]. However, the license and permit system was abolished when the Swedish Data Act was replaced by the Personal Data Act in 1998 [45, p. 7/26]. 
means to the de facto independence of the Swedish DPA is not yet clarified and will be subject to further research.

\section{Conclusion}

This paper presents an exploratory perspective on DPAs in the EU, drawing on theories of regulation such as the concept of the regulatory state and IRAs. Since there is no clear framework for a political science analysis of DPAs, theoretical and methodological approaches to IRAs have proven to be useful in identifying, assessing and systematically comparing central features of DPAs such as their independence.

For example, Gilardi and Thatcher have demonstrated interesting ideas as to how to measure independence using quantitative methods. Whereas Gilardi set up an independence index that aims to measure the formal independence of IRAs from governmental actors, Thatcher expands his analysis to include informal sources of influence such as politicization and revolving doors. Despite the shortcomings of the approaches, both researchers help to identify key determinants of formal and de facto independence.

Independence of DPAs is particularly threatened, since privacy regulators face two fronts of regulatees, i.e. business and political actors. Although the EU Data Protection Directive specifically stipulates that DPAs shall act with "complete independence", Member States are given a certain degree of latitude in transposing the provisions into national legislation. That is why this paper examines the legally stipulated independence status of DPAs in three EU Member States, each state representing a particular tradition of policy-making within the European Union.

We can conclude that Germany, Poland and Sweden are taking advantage of the possibility to flexibly apply the "complete independence" requirement of the Directive. However, there are huge differences to the degree to which the notion of independence is (over-) strechted in national data protection legislations. Whereas the Polish DPA seems to fulfil most formal independence requirements, the FfDF in Germany and particularly the DIB in Sweden clearly lack the same.

Most importantly, the traditionally close link between DPAs and certain ministries in Sweden and Germany appears to have resulted in a rather one-dimensional accountability relationship with the government. At the same time, accountability and control are often confused, as the "functional independence" approach, presented during the discussed ECJ trial by German representatives, obviously demonstrates.

Thus, not only the exclusive right to nominate and appoint the head of the DPA, but also the opportunity to veto against personnel policy decisions lies with the government. While this is the case in Germany and Sweden, the Polish DPA has no attachment whatsoever to any ministry or governmental agency. Being appointed by and only accountable to both chambers of parliament, the Polish Inspector General has far-reaching discretion in managerial and financial domains within the authority. As the German data protection commissioner, the Inspector General is financed by a parliamentary act; unlike in Sweden, where the DIB has to rely on the Ministry of Justice's negotiations with the treasury.

All in all, there is significant variation in the legally stipulated form of governmental influence on DPAs. Even though these findings do not necessarily mean that DPAs 
lacking formal independence are not independent in practice, research on IRAs suggests that causal and statistical linkages between de jure and de facto independence exist. In order to corroborate or falsify the findings on the formal independence of DPAs, the collection of primary data with regards to their de facto independence is absolutely essential. That is why interviews with DPA officials will represent a central part of further research within the mentioned dissertation project.

\section{References}

1. Majone, G.: The rise of the regulatory state in Europe. West European Politics 17, 77-101 (1994), http: //www.tandfonline.com/doi/abs/10.1080/01402389408425031

2. Majone, G.: Regulating Europe. Routledge, London (1996)

3. Majone, G.: From the positive to the regulatory state: Causes and consequences of changes in the mode of governance. Journal of Public Policy 17, 139-167 (1997), http://www.jstor.org/stable/10.2307/4007608

4. Bennett, C.J., Raab, C.D.: The Governance of Privacy: Policy Instruments in Global Perspective, 2nd and updated edn. MIT Press, Cambridge (2006)

5. Hood, C.: Regulation inside government: Waste watchers, quality police, and sleaze-busters. Oxford University Press, Oxford (1999)

6. Gilardi, F.: Policy credibility and delegation to independent regulatory agencies: A comparative empirical analysis. Journal of European Public Policy 9, 873-893 (2002), http: / / www.tandfonline.com/doi/abs/10.1080/1350176022000046409

7. Hooghe, L., Marks, G.: Multi-level governance and European integration. Rowman \& Littlefield, Lanham (2001)

8. Caporaso, J.A.: The European Union and forms of state: Westphalian, regulatory or post modern? JCMS: Journal of Common Market Studies 34, 29-52 (1996),

http://onlinelibrary.wiley.com/doi/10.1111/j.1468-5965.1996. tb00559.x/abstract

9. Eberlein, B., Grande, E.: Beyond delegation: transnational regulatory regimes and the EU regulatory state. Journal of European Public Policy 12, 89-112 (2005), http://www.tandfonline.com/doi/abs/10.1080/1350176042000311925

10. Wilks, S., Bartle, I.: The unanticipated consequences of creating independent competition agencies. West European Politics 25, 148-172 (2002),

http: //www.tandfonline.com/doi/abs/10.1080/713601589

11. Quintyn, M.: Independent agencies: More than a cheap copy of independent central banks? Constitutional Political Economy 20, 267-295 (2009), http://www.springerlink.com/content/r83m085v5t86w600/

12. Thatcher, M.: Regulation after delegation: Independent regulatory agencies in Europe. Journal of European Public Policy 9, 954-972 (2002),

http: / / www.tandfonline.com/doi/abs/10.1080/1350176022000046445

13. Gilardi, F.: The institutional foundations of regulatory capitalism: The diffusion of independent regulatory agencies in Western Europe. The Annals of the American Academy of Political and Social Science 598, 84-101 (2005), http: //ann.sagepub.com/content/598/1/84.short

14. Cukierman, A., Web, S.B., Neyapti, B.: Measuring the independence of central banks and its effect on policy outcomes. The World Bank Economic Review 6, 353-398 (1992), http://wber.oxfordjournals.org/content/6/3/353.short 
15. Hanretty, C., Koop, C.: Measuring the formal independence of regulatory agencies. Journal of European Public Policy, 1-19 (2011),

http: / /www.tandfonline.com/doi/abs/10.1080/13501763.2011. 607357

16. Maggetti, M.: De facto independence after delegation: A fuzzy-set analysis. Regulation \& Governance, 271-294 (2007), http://onlinelibrary.wiley.com/doi/10.1111/j.1748-5991.2007. $00023 . x /$ full

17. Gilardi, F., Maggetti, M.: The independence of regulatory authorities. In: Levi-Faur, D. (ed.), Handbook on the Politics of Regulation. Edward Elgar, Cheltenham (forthcoming)

18. Hanretty, C.: Explaining the de facto independence of public broadcasters. British Journal of Political Science 40, 75-89 (2009),

http://journals.cambridge.org/action/displayfulltext?type= $1 \& f i d=7045008 \& j i d=J P S \& v O l u m e I d=40 \& i$ ssueId=01\&aid=7045000

19. Hayo, B., Voigt, S.: Explaining de facto judicial independence. International Review of Law and Economics 27, 269-290 (2007),

http://www.sciencedirect.com/science/article/pii/ S0144818807000567

20. Gutwirth, S.: Privacy and the information age. Rowman \& Littlefield Publishers, Lanham (2002)

21. Directive 95/46/EC of the European Parliament and of the Council of 24 October 1995 on the protection of individuals with regard to the processing of personal data on the free movement of such data. Official Journal of the European Communities L 281, 31-50 (1995), http://eur-lex.europa.eu/LexUriServ/LexUriServ.do?uri=CELEX: 31995L0046:EN:NOT

22. Hustinx, P.: The role of data protection authorities. In: Gutwirth, S., Poullet, Y., Hert, P., Terwangne, C., Nouwt, S. (eds.) Reinventing Data Protection?, pp. 131-137. Springer, Dodrecht (2009),

http: //www.springerlink.com/content/u42572u8138747n3/

23. Simitis, S.: From the market to the polis: The EU Directive on the protection of personal data. Iowa Law Review 80, 445-469 (1994),

http://heinonline.org/HOL/LandingPage?collection=journals \&handle=hein.journals /ilr80\&div=26\&id=\&page=

24. Castles, F.: Families of nations: Patterns of public policy in Western democracies. Dartmouth, Aldershot Hants England; Brookfield Vt. USA (1993)

25. Castles, F.: Comparative public policy: Patterns of post-war transformation. Edward Elgar, Cheltenham (1998)

26. Hessian Data Protection Act, Hesse (Germany) (1970), www.datenschutz.rlp.de/downloads/hist/ldsg_hessen_1970.pdf

27. Judgment of the Court (Grand Chamber) of 9 march 2010. European Commission v Federal Republic of Germany. Failure of a Member State to Fulfil Obligations - Directive 95/46/EC - Protection of Individuals with Regard to the Processing of Personal Data and the Free Movement of Such Data - Article 28(1) - National Supervisory Authorities - Independence Administrative Scrutiny of Those Authorities. Case c-518/07 (2010), http://curia.europa.eu/juris/documents.jsf ?pro=\&lgrec=en\&nat= $\&$ oqp $=\& l \mathrm{~g}=\&$ date $=\&$ language $=$ en $\&$ jur $=\mathrm{C} \% 2 \mathrm{CT} \div 2 \mathrm{CF} \& \mathrm{Cit}=$ none $\% 252 \mathrm{CC}$ $\% 252 \mathrm{CCJ} \% 252 \mathrm{CR} \div 252 \mathrm{C} 2008 \mathrm{E} \div 252 \mathrm{C} \div 252 \mathrm{C} \div 252 \mathrm{C} \div 252 \mathrm{C} \div 252 \mathrm{C} \div 252 \mathrm{C}$ $\% 252 \mathrm{C} \% 252 \mathrm{C} \% 252 \mathrm{C} \% 252 \mathrm{Ctrue} \% 252 \mathrm{Cfal}$ se $\% 252 \mathrm{Cfal}$ se\&num $=\mathrm{C}-518$ $\circ 252 \mathrm{~F} 07 \& \mathrm{td}=\mathrm{ALL} \& \mathrm{pCs}=0 \& \mathrm{cavg}=\& \mathrm{page}=1 \& \mathrm{mat}=$ or $\& \mathrm{jge}=\&$ for $=\& \mathrm{cid}=1757448$ 
28. Dammann, U.: Bundesbeauftragter für den Datenschutz und die Informationsfreiheit. In: Simitis, S. (ed.) Bundesdatenschutzgesetz - Kommentar, 7th edn., Nomos, Baden-Baden (2011)

29. Budget of the Federal Ministry of the Interior 2011, Germany (2011), http://www . bundesfinanzministerium.de/bundeshaushalt2011/pdf/epl06.pdf

30. Federal Data Protection Act, Germany, 2009 (1990), http: //www.bfdi.bund.de/EN/DataProtectionActs/Artikel/BDSG _idFv01092009.pdf?_blob=publicationFile

31. Act on the Protection on Personal Data, Poland, 2004 (1997), http://www.giodo.gov.pl/plik/id_p/180/j/en/

32. Budget of the Bureau of the Inspector General for personal data protection 2009, Poland (2009), http://www.giodo.gov.pl/432/j/en/

33. The statutes of the Bureau of the Inspector General for Personal Data Protection, Poland (2006), http://www.giodo.gov.pl/data/filemanager_en/99.pdf

34. Appendix to the Regulation no. 29/2007 by the Inspector General for the Protection of Personal Data - Organisational regulations of the Bureau of the Inspector General for Personal Data Protection, Poland (2007), http://www.giodo.gov.pl/plik/id_p/126/j/en/

35. Bennett, C.: Regulating privacy: Data protection and public policy in Europe and the United States. Cornell University Press, Ithaca (1992)

36. Act on supervision of certain crime-fighting activities, Sweden (2007:980) (2007), http://www. sweden.gov.se/download/1f30a0f0.pdf?major=1\&minor= 95172\&cn=attachmentPublDuplicator_0_attachment

37. Personal Data Act, Sweden (1998), http: / /www.sweden.gov.se/content/1/c6/01/55/42/b451922d.pdf

38. Brochure of the Data Inspection Board: What on earth does the Data Inspection Board do?: A portrait of the swedish Data Inspection Board, http: //www. datainspektionen.se/Documents / datainspektionenpresentation-eng.pdf

39. Government Decision for the Budget 2011 of the Data Inspection Board, I:59, Ministry of Justice, Sweden (2010),

http://www.esv.se/Verktyg-stod/Statsliggaren/Regleringsbrev / ?RBID=12916

40. Stewart, B.: A comparative survey of data protection authorities - Part 1: Form and structure. Privacy Law and Policy Reporter 11 (2004)

41. Swedish Statute Book - Governments regualtions, SFS 2007:515, Sweden (2007)

42. Employment Protection Act, Sweden (1982:80) (1982),

http: //www. sweden.gov.se/download/9b9ee182 .pdf?major=1\&minor= 76536\&cn=attachmentPublDuplicator_0_attachment

43. Response to an information request, Data Inspection Board (2011)

44. Flaherty, D.: Protecting privacy in surveillance societies: The federal Republic of Germany, Sweden, France, Canada, and United States. University of North Carolina Press, Chapel Hilland (1989)

45. Brochure of the MInistry of Justice: Personal Data Protection - Information on the Personal Data Act, Ministry of Justice, Sweden (2006), http: / / www. regeringen.se/download/0ea2c0eb.pdf?major=1\&minor= 74363\&cn=attachmentPublDuplicator_0_attachment

46. Swedish Statute Book - Regulation with instructions for the Data Inspection Board, SFS 2007:975, Sweden (2007)

47. Staff Representative Ordinance, 1987:1101, Sweden (1987) 